\title{
Experimental and numerical investigations of the steel sheets formability with hydroforming
}

\author{
Radu Vasile ${ }^{1, *}$, Sever-Gabriel Racz ${ }^{1}$, and Octavian Bologa ${ }^{1}$ \\ ${ }^{1}$ Department of Industrial Machinery and Equipment "Lucian Blaga" University, Sibiu, Romania
}

\begin{abstract}
The present paper focuses on analyzing the forming capacity of steel blanks with hydroforming process. For this research steel sheets have been in focus for numerical and experimental analysis. The main advantages for this materials are good surface finish, excellent forming capacity and close tolerances, appealing advantages for manufacturers. A finite element model has been developed from data obtained through tensile tests and forming limit curves. A newly developed hydroforming press has been used to carry out the forming experiments. Side-by-side analysis between numerical and experimental results concludes the experiment.
\end{abstract}

\section{Introduction}

Automotive, aviation, aerospace and medical industries focus research towards lighter materials such as aluminum alloys, magnesium alloys, high-strength steels and titanium alloys. The advantages of these materials are used to reduce the weight of the parts and to increase the structure rigidity of the future product. All these efforts will result in lower energy consumption, fewer carbon dioxide emissions and lower costs for the manufacturer and the end user. But producing high quality products forces researchers to create or improve production technologies to increase the material deformability limits [1-2]. Therefore the present research is presenting a different approach towards hydroforming press concept in forming two different steel materials.

\section{Materials used in this research}

The numerical and experimental researches were made in order to evaluate the forming behavior of steels DC01 and DX51D. The first material, DC01, is an uncoated mild steel used in typical deep-drawing applications, also known as 1.0330 by DIN EN 10346. The second material researched is DX51D, a mild galvanized steel grade for cold forming, also known as 1.0226. It is non-ageing steel designed for deep and extra deep drawing that is covered with a layer of zinc for good resistance to corrosion [3-4].

The chemical composition of both materials, in percent by mass, is presented in Table 1 [3-5].

\footnotetext{
* Corresponding author: r.vasile@ulbsibiu.ro
} 
The physical and mechanical properties of both materials are presented in Table 2 [3-7], where $\rho$ - density, $E$ - Young's modulus, $\mathrm{R}_{\mathrm{p} 0.2}-$ yield stress, $\mathrm{R}_{\mathrm{m}}-$ tensile stress, $r-$ anisotropy, $v$ - Poisson's ratio, $n$ - strain hardening exponent, $K$ - strength coefficient.

Table 1. Material chemical composition maximum values $[\mathrm{wt} \%]$.

\begin{tabular}{|c|c|c|}
\hline $\begin{array}{l}\text { Material } \\
\text { Element }\end{array}$ & DC01 & DX51D \\
\hline $\mathrm{Fe}$ & 98 & $\begin{array}{ll} & 99.3 \\
0 & \end{array}$ \\
\hline $\mathrm{Ti}$ & - & 0.30 \\
\hline $\mathrm{Si}$ & - & 0.50 \\
\hline $\mathrm{Mn}$ & 0.6 & 0.60 \\
\hline $\mathrm{P}$ & 0.045 & 0.10 \\
\hline $\mathrm{S}$ & 0.045 & 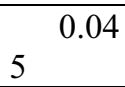 \\
\hline $\mathrm{C}$ & 0.12 & 0.12 \\
\hline
\end{tabular}

Table 2. Material physical and mechanical properties.

\begin{tabular}{|c|c|c|}
\hline \multicolumn{2}{|c|}{ Material } & DX51D \\
Property & DC01 & DX5 \\
\hline$\rho\left[\mathrm{kg} / \mathrm{dm}^{3}\right]$ & \multicolumn{2}{|c|}{7.83} \\
\hline$E[\mathrm{GPa}]$ & \multicolumn{2}{|c|}{210} \\
\hline $\mathrm{R}_{\mathrm{p} 0.2}[\mathrm{MPa}]$ & $140-280$ & $\geq 140$ \\
\hline $\mathrm{R}_{\mathrm{m}}[\mathrm{MPa}]$ & $270-410$ & $270-500$ \\
\hline $\mathrm{A}_{80}[\%]$ & $\geq 28$ & $\geq 22$ \\
\hline$v[-]$ & 0.35 & 0.30 \\
\hline$r[-]$ & 1.53 & 0.84 \\
\hline$n[-]$ & 0.21 & 0.2 \\
\hline$K[\mathrm{MPa}]$ & 619 & 593 \\
\hline
\end{tabular}

\subsection{Uniaxial tensile test}

The uniaxial tensile tests were carried out on an Instron 5587 testing machine. The test samples of $120 \times 20 \times 1$ [ $\mathrm{mm}^{3}$ ] for both materials, in accordance with ISO 6892-1:2009 [8]. The tensile machine was controlled by Blue-hill proprietary software and GOM Aramis systems was used instead of an extensometer. With this experimental configuration the main mechanical characteristics have been determined. The determined values are presented in Table 3, where $\sigma_{\max }$ - maximum stress and $\varepsilon_{\max }$ - maximum strain.

Table 3. Determined material characteristics.

\begin{tabular}{|c|c|c|c|c|c|c|}
\hline Material & \multicolumn{3}{|c|}{ DC01 } & \multicolumn{3}{c|}{ DX51D } \\
\hline RD & \multirow{2}{*}{$\mathbf{0}^{\circ}$} & \multirow{2}{*}{$\mathbf{4 5}^{\circ}$} & $\mathbf{9 0}^{\circ}$ & $\mathbf{0}^{\circ}$ & $\mathbf{4 5}^{\circ}$ & $\mathbf{9 0}^{\circ}$ \\
\hline$E[\mathrm{GPa}]$ & 64.98 & 67.35 & 71.7 & 70.2 & 73.84 & 64.69 \\
\hline $\mathrm{R}_{\mathrm{p} 0.2}[\mathrm{MPa}]$ & 181.28 & 190.96 & 188.95 & 349.93 & 349.85 & 341.6 \\
\hline $\mathrm{R}_{\mathrm{m}}[\mathrm{MPa}]$ & 328.86 & 343.88 & 332.62 & 396.03 & 405.95 & 394.81 \\
\hline $\mathrm{A}[\%]$ & 37.43 & 34.65 & 35.39 & 23.74 & 23.41 & 23.33 \\
\hline$\sigma_{\max }[\mathrm{MPa}]$ & 431.47 & 443.97 & 429.32 & 469.35 & 483.78 & 473.18 \\
\hline$\varepsilon_{\max }[-]$ & 0.32 & 0.3 & 0.3 & 0.21 & 0.21 & 0.21 \\
\hline$n[-]$ & 0.24 & 0.24 & 0.23 & 0.14 & 0.15 & 0.16 \\
\hline$K[\mathrm{MPa}]$ & 590.16 & 614.81 & 591.38 & 605.53 & 626.03 & 621.94 \\
\hline$r[-]$ & 1.770 & 1.104 & 2.003 & 1.383 & 0.837 & 1.092 \\
\hline $\bar{r}[-]$ & \multicolumn{3}{|c|}{0.795} & & \multicolumn{3}{c|}{0.4037} \\
\hline$\Delta r[-]$ & \multicolumn{3}{|c|}{0.783} & \\
\hline
\end{tabular}

The true strain-stress curves for three directions from the sheet rolling direction RD have been determined, but only the samples for $0^{\circ}$ to $\mathrm{RD}$, compared side-by-side are presented in Fig. 1 and Fig. 2. As can be seen DX51D offers $20 \%$ more stress, but $34 \%$ less 
strain behavior compared to DC01. Also there can be noted that DX51D present an apparent flow, at almost $93 \%$ more stress compared to DC01.

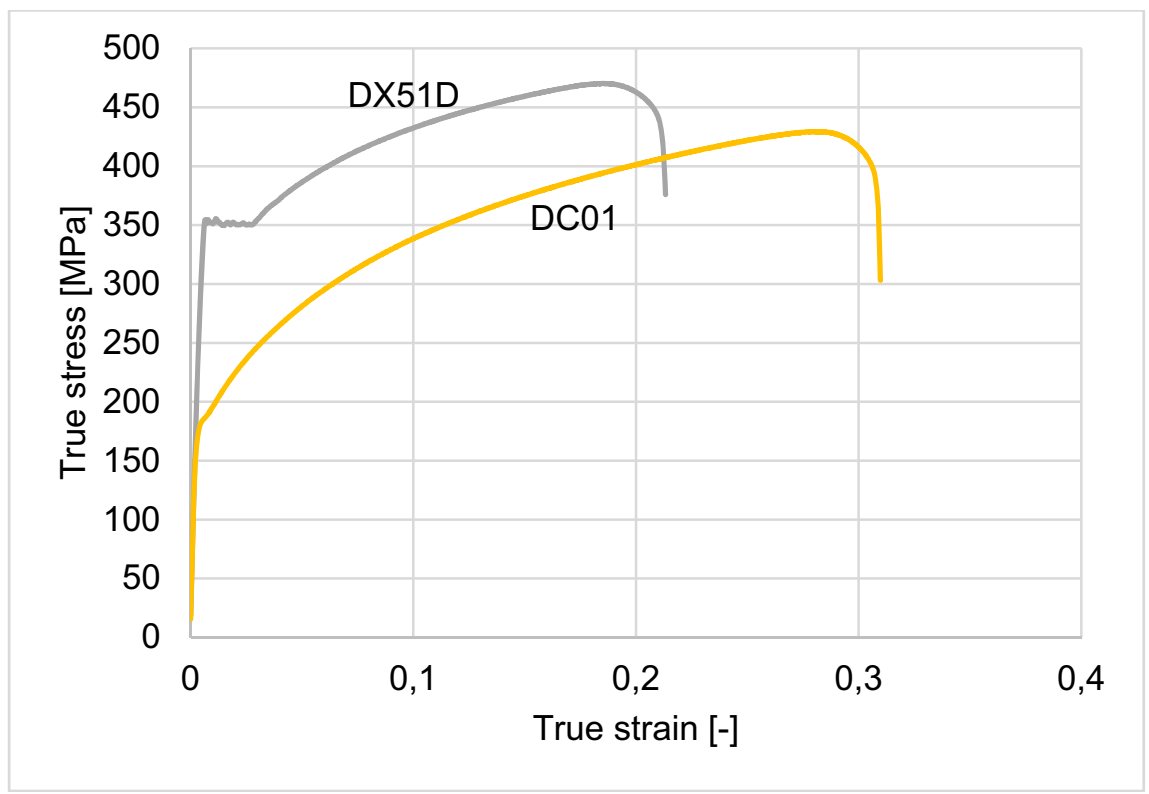

Fig. 1. True strain-stress curves for $0^{\circ}$ to rolling direction.

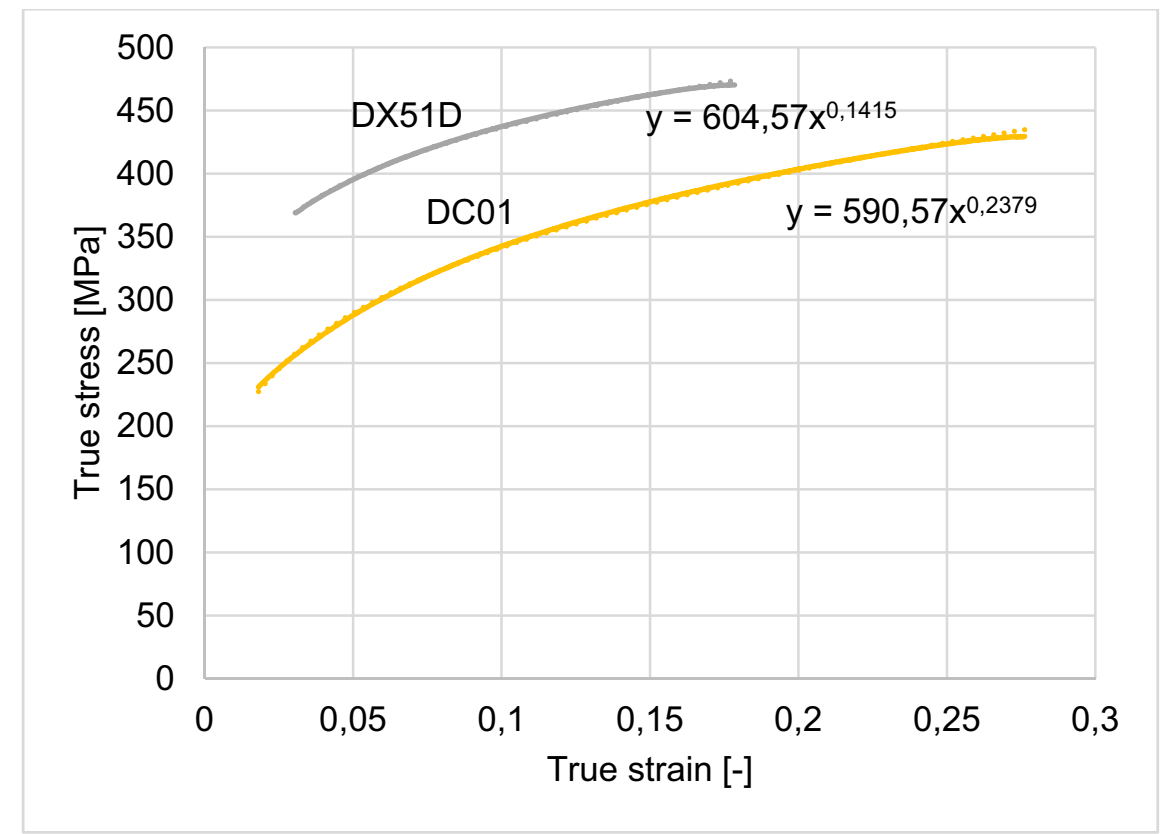

Fig. 2. Determined strain hardening curves. 


\subsection{Forming limit curve}

The tests were carried out using the following experimental setup - a modular deep drawing unit, with exchangeable active elements, connected to a hydraulic high pressure unit and two CCD cameras connected to GOM Aramis - the optical strains measurement system. Forming limit curves have been determined experimentally by using several load paths of the test samples, between the uniaxial tension and the equibiaxial stretching. This has been obtained by realizing different test specimen geometry, suggested by Hašek [9-12]. The samples were laser cut and following the same procedure as before, the remaining burrs were removed and the samples surface covered by a layer of white matt paint to eliminate reflections and a cloud of black matt paint to obtain the diffuse network of points. Every test sample was deep drawn with a hemispherical punch until fracture and at the same time monitored by Aramis system. The test has been in compliance with standard ISO 120042:2008 and the results are represented in Fig. 3 [13]. It can be clearly observed a better forming capacity for DC01.

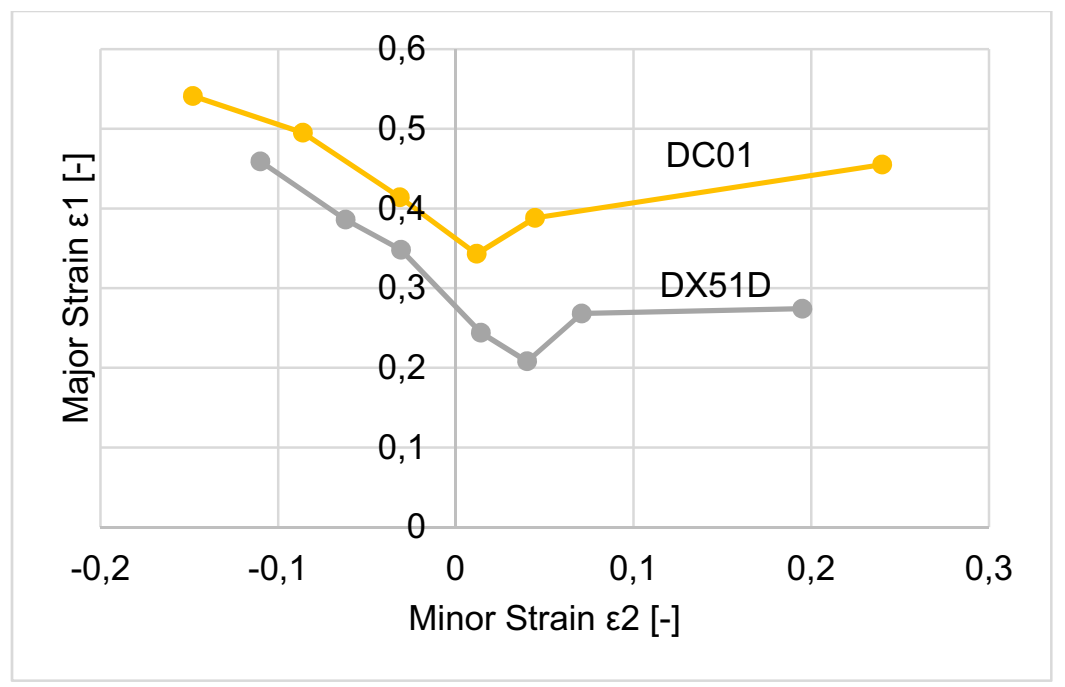

Fig. 3. Determined forming limit curves.

\section{Numerical simulation}

The hydroforming process has been analyzed with the help of Abaqus/Explicit software with the objective to determine the major and minor principal strains and the researched materials forming limits. A parametrized geometric model with finite elements, presented in Fig. 4, was created using the built-in tridimensional module of the program. The researched materials characteristics and parameters were experimentally determined and introduced in the program to accurately define the model in the dynamic analysis. The process parameters and values are presented in Table 4 , these are $\mathrm{R}-$ die radius, $\mathrm{p}_{\mathrm{s}}-$ retaining pressure, $\mathrm{p}_{\mathrm{h}}-$ hydroforming pressure and $\mathrm{t}_{0}-$ blank initial thickness. The Ramberg-Osgood equation was used to calculate the plastic strain and Hill yield criterion was been used in order to take into account the materials anisotropy. For evaluating the materials instability and tearing during the proposed hydroforming process, the plastic instability criterion was used. The blank was meshed with shell elements, with four nodes and reduced integration on the middle surface, with five integration points in width. The 
retaining ring and the die were meshed using tridimensional four nodes rigid elements. The retaining and the hydroforming pressure were applied five times quicker than reality.

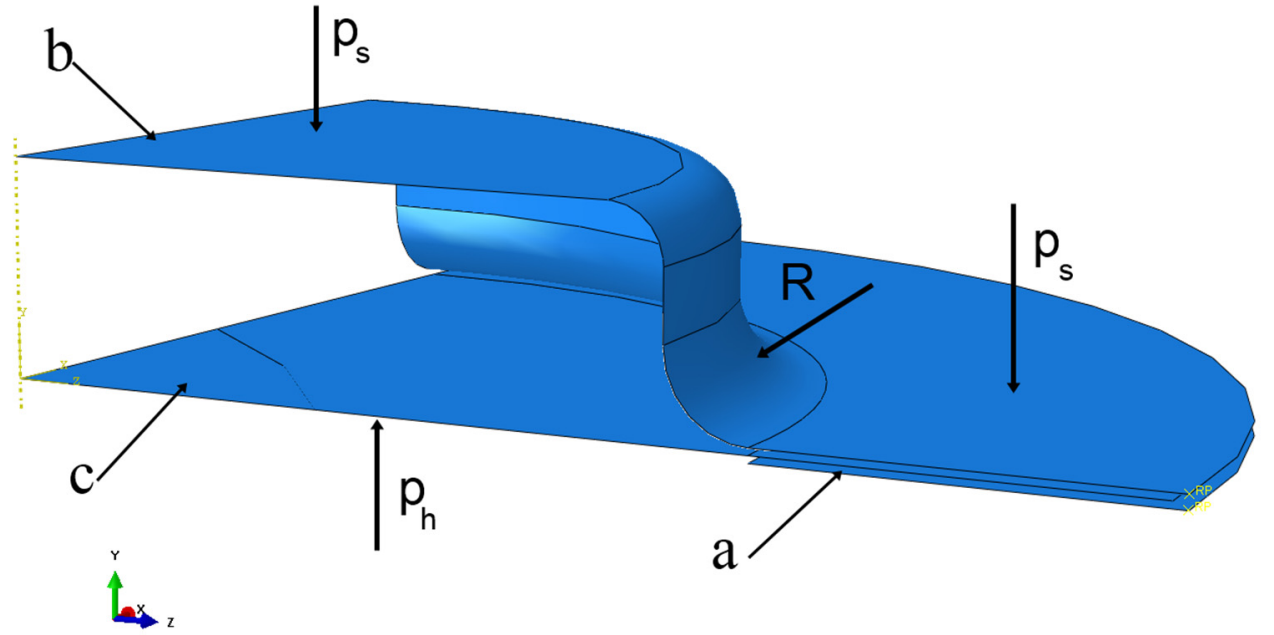

Fig. 4. Numerical simulation modelling and process parameters. $\mathrm{a}$ - retaining ring, $\mathrm{b}$ - die, $\mathrm{c}$ - blank.

Table 4. Model and process parameters.

\begin{tabular}{|c|c|c|c|c|c|c|c|c|}
\hline $\begin{array}{l}\text { Parameter } \\
\text { Material }\end{array}$ & \multicolumn{3}{|c|}{$\mathbf{R}[\mathrm{mm}]$} & ps [bar] & \multicolumn{3}{|c|}{ ph [bar] } & to $[\mathrm{mm}]$ \\
\hline $\begin{array}{l}\text { DC01 } \\
\text { DX51D }\end{array}$ & 4 & 6 & 8 & 250 & 150 & 250 & 350 & 1 \\
\hline
\end{tabular}

The results obtained from numerical simulation are presented in Fig. 5 and Fig. 6. It can be noted that the biggest differences observed on the images are not the local strains compared, but the anisotropy distribution by influencing local strain values.

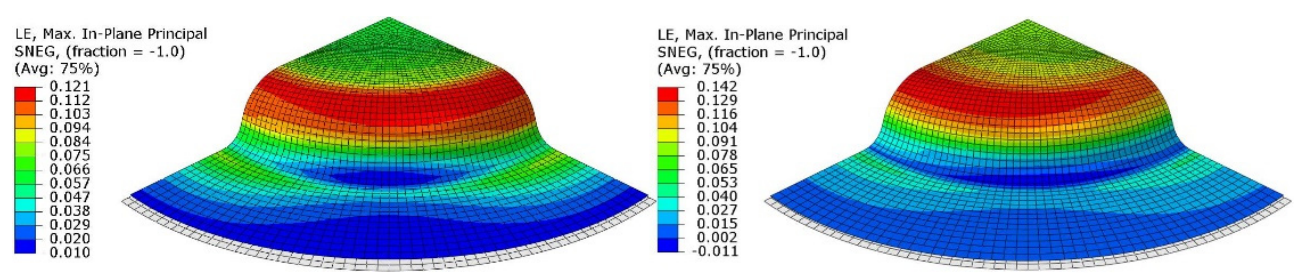

Fig. 5. Major strain results $\mathrm{R}=6[\mathrm{~mm}] \mathrm{ph}_{\mathrm{h}}=350$ [bar $]$.

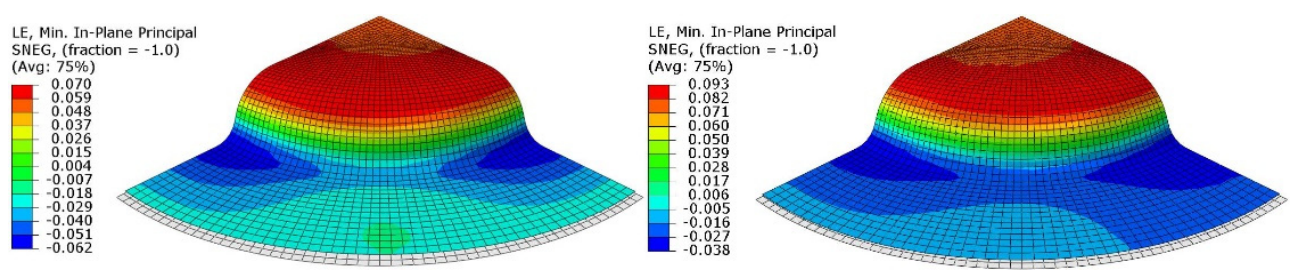

Fig. 6. Minor strain results $R=6[\mathrm{~mm}] \mathrm{ph}_{\mathrm{h}}=350$ [bar]. 


\section{Experimental research}

Hydroforming experimental investigations were carried out on a new hydroforming solution developed by the authors. Combining design knowledge with the study of hydroforming die concepts by field specialists and with the research requirements the following hydroforming solution was built. The unique hydroforming concept as seen in Fig. 7 is completely developed by the authors. The solution was built from scratch, having a new shape and modulation concept unseen in other researches.

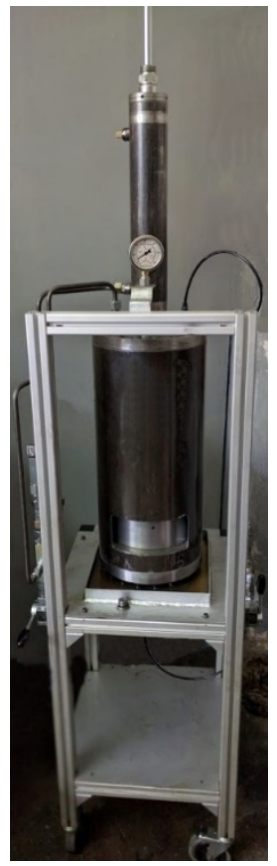

Fig. 7. Hydroforming solution, unique concept developed by the authors.

The main process parameters $-p_{s}$ and $p_{f}$ - are monitored in real-time with a pressure transducer, as represented in Fig. 8. Also the blanks have been covered electrolitically with a calibrated network of points in order to optically measure the major and minor strains with GOM Argus system, image capture and computation are presented in Fig. 9.

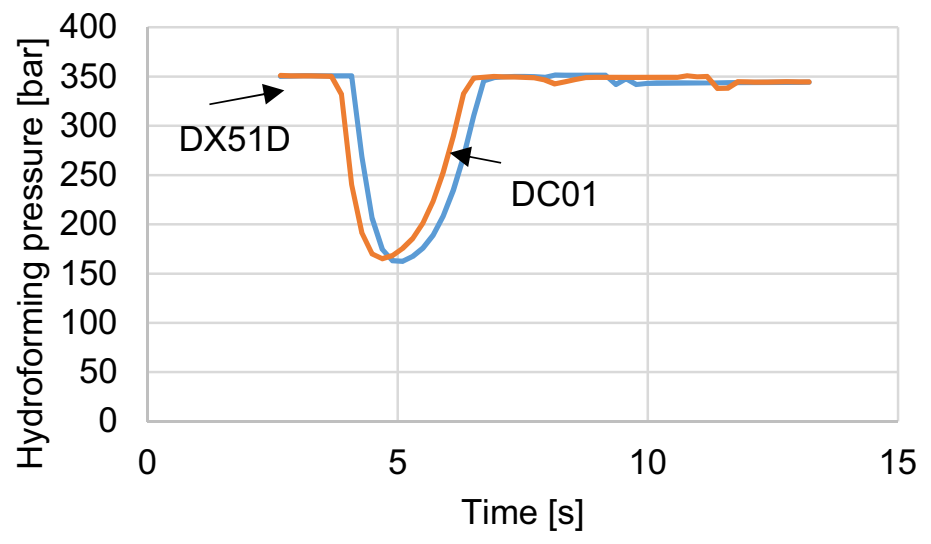

Fig. 8. Hydroforming pressure for $\mathrm{R}=6[\mathrm{~mm}] \mathrm{p}_{\mathrm{h}}=350[\mathrm{bar}]$. 


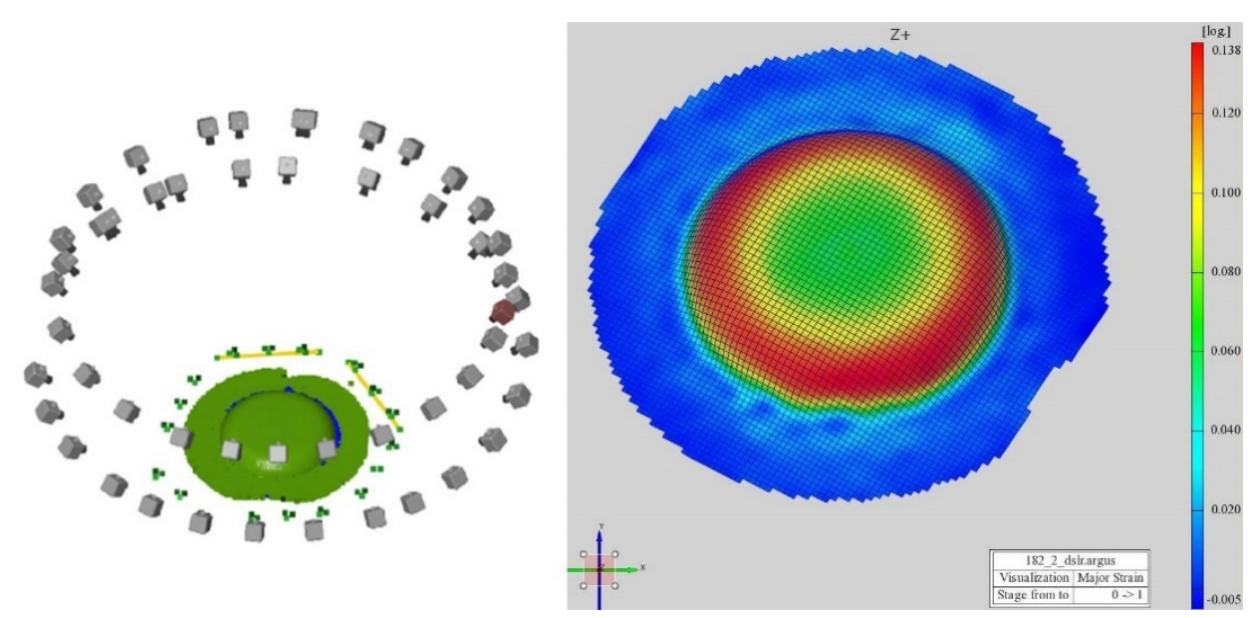

Fig. 9. Measuring local strain on the drawn part with GOM Argus System.

The main objective of the present research was to determine and study the influence of die radius and hydroforming pressure variation for two representative steel materials. The process parameters are introduced in both numerical and experimental analysis to compare the material forming limits by comparing the reached local strain.

The numerical simulation results were side-by-side compared with the experimental measured results. The maximum relative error between numerical and experimental results is below five percent. The values are represented in Table 5 .

Table 5. Numerical and experimental results for hydroforming.

\begin{tabular}{|c|c|c|c|c|c|c|c|c|}
\hline \multirow[t]{2}{*}{ No. } & \multirow[t]{2}{*}{ Material } & \multirow{2}{*}{$\begin{array}{c}\text { Pressure } \\
\text { ph }[\text { bar }]\end{array}$} & \multirow{2}{*}{$\begin{array}{c}\text { Radius } \\
{[\mathrm{mm}]}\end{array}$} & \multicolumn{2}{|c|}{ Numerical simulation } & \multicolumn{2}{|c|}{$\begin{array}{c}\text { Experimental } \\
\text { results }\end{array}$} & \multirow{2}{*}{$\begin{array}{l}\text { Error } \\
{[\%]}\end{array}$} \\
\hline & & & & $\varepsilon_{1}[-]$ & $\varepsilon_{2}[-]$ & $\varepsilon_{1}[-]$ & $\varepsilon_{2}[-]$ & \\
\hline 1 & DC01 & \multirow{2}{*}{150} & \multirow{6}{*}{8} & 0.075 & 0.058 & 0.076 & 0.059 & 1.53 \\
\hline 2 & DX51D & & & 0.088 & 0.073 & 0.091 & 0.076 & 3.76 \\
\hline 3 & DC01 & \multirow{2}{*}{250} & & 0.096 & 0.062 & 0.092 & 0.063 & 2.89 \\
\hline 4 & DX51D & & & 0.113 & 0.080 & 0.116 & 0.081 & 1.95 \\
\hline 5 & DC01 & \multirow{2}{*}{350} & & 0.116 & 0.064 & 0.119 & 0.065 & 2.00 \\
\hline 6 & DX51D & & & 0.131 & 0.083 & 0.127 & 0.084 & 2.31 \\
\hline \multirow[t]{2}{*}{ No. } & \multirow[t]{2}{*}{ Material } & \multirow{2}{*}{$\begin{array}{c}\text { Pressure } \\
p_{h}[\text { bar] }\end{array}$} & \multirow{2}{*}{$\begin{array}{c}\text { Radius } \\
{[\mathbf{m m}]}\end{array}$} & \multicolumn{2}{|c|}{ Numerical simulation } & \multicolumn{2}{|c|}{$\begin{array}{l}\text { Experimental } \\
\text { results }\end{array}$} & \multirow{2}{*}{$\begin{array}{l}\text { Error } \\
{[\%]}\end{array}$} \\
\hline & & & & $\varepsilon_{1}[-]$ & $\varepsilon_{2}[-]$ & $\varepsilon_{1}[-]$ & $\varepsilon_{2}[-]$ & \\
\hline 1 & DC01 & \multirow{2}{*}{150} & \multirow{6}{*}{6} & 0.078 & 0.062 & 0.080 & 0.065 & 3.70 \\
\hline 2 & DX51D & & & 0.093 & 0.078 & 0.095 & 0.081 & 3.00 \\
\hline 3 & DC01 & \multirow{2}{*}{250} & & 0.101 & 0.067 & 0.106 & 0.069 & 3.97 \\
\hline 4 & DX51D & & & 0.123 & 0.090 & 0.126 & 0.092 & 2.33 \\
\hline 5 & DC01 & \multirow{2}{*}{350} & & 0.121 & 0.070 & 0.126 & 0.073 & 4.38 \\
\hline 6 & DX51D & & & 0.142 & 0.093 & 0.141 & 0.095 & 1.43 \\
\hline \multirow[t]{2}{*}{ No. } & \multirow[t]{2}{*}{ Material } & \multirow{2}{*}{$\begin{array}{c}\text { Pressure } \\
\text { ph [bar] }\end{array}$} & \multirow{2}{*}{$\begin{array}{c}\text { Radius } \\
{[\mathrm{mm}]}\end{array}$} & \multicolumn{2}{|c|}{ Numerical simulation } & \multicolumn{2}{|c|}{$\begin{array}{l}\text { Experimental } \\
\text { results }\end{array}$} & \multirow{2}{*}{$\begin{array}{l}\text { Error } \\
{[\%]}\end{array}$} \\
\hline & & & & $\varepsilon_{1}[-]$ & $\varepsilon_{2}[-]$ & $\varepsilon_{1}[-]$ & $\varepsilon_{2}[-]$ & \\
\hline 1 & DC01 & \multirow{2}{*}{150} & \multirow{6}{*}{4} & 0.083 & 0.067 & 0.086 & 0.065 & 3.00 \\
\hline 2 & DX51D & & & 0.098 & 0.084 & 0.095 & 0.074 & 4.56 \\
\hline 3 & DC01 & \multirow{2}{*}{250} & & 0.108 & 0.073 & 0.112 & 0.076 & 3.91 \\
\hline 4 & DX51D & & & 0.134 & 0.101 & 0.137 & 0.106 & 3.60 \\
\hline 5 & $\mathrm{DC} 01$ & \multirow{2}{*}{350} & & 0.130 & 0.077 & 0.134 & 0.078 & 2.19 \\
\hline 6 & DX51D & & & 0.158 & 0.107 & 0.163 & 0.108 & 2.05 \\
\hline
\end{tabular}




\section{Conclusion}

The research was based on determining many material characteristics to define as accurately as possible the numerical model. This model was compared to the experimental drawn parts with an own built custom solution. All experimental results are compared and analyzed extensively with those obtained by numerical simulation and the resulted error percentage is less than $5 \%$. In this way the accuracy of the experimental results was evaluated and the finite element model was validated. For all the studied materials, both major and minor strains and the thickness reduction have the same tendency of variation for the die radius and the hydroforming pressure, that is, the results increase with decreasing radius and increasing hydroforming pressure.

Further research can be carried out by researching variable process parameter like blank holder pressure. This can be done be designing an experiment method with three influence factors with three variable values each.

This work was carried out with the support by Flupec Hydraulics \& Pneumatics Sibiu - private company where the hydroforming press was manufactured, assembled and forming tests were carried out.

\section{References}

1. I. G., D. L. R. and M. F., Sustainability issues in sheet metal forming processes, Jou. Cleaner Prod., 19, 4, 337-347, (2011)

2. K. M., Hydroforming for Advanced Manufacturing, Woodhead Publishing, (2008)

3. EN 10130, Cold rolled low carbon steel flat products for cold forming. Technical delivery conditions, (2006)

4. E. 10346, Continuously hot-dip coated steel flat products. Technical delivery conditions, (2009)

5. M. Hill, Marks' Standard Handbook for Mechanical Engineers 8th Ed., McGraw Hill Book Company, (1978)

6. K. Siegert and S. Wagner, "TALAT Lecture 3701," (1994). [Online]. Available: http://core.materials.ac.uk/repository/eaa/talat/3701.pdf. (Accessed 04 2016)

7. D. Banabic, G. Dragos and I. Bichis, "Influence of Variability of Mechanical Data on Forming Limits Curves," (2010). [Online]. Available: http://comod.utcluj.ro/documents/articles/Banabic_Steel\%20Research\%20_Int.\%20201 0.pdf. (Accessed 06 2016)

8. Metallic materials -- Tensile testing -- Part 1: Method of test at room temperature, ISO 6892-1, (2009)

9. J. W. Signorelli and M. d. 1. A. Bertinetti, Self-Consistent Homogenization Methods for Predicting Forming Limits of Sheet Metal, in Metal Forming - Process, Tools, Design, InTech, 175-210, (2012)

10. D. Banabic, L. Paraianu, G. Dragos, I. Bichis and D. S. Comsa, An improved version of the modified maximum force criterion (MMFC) used for predicting the localized necking in sheet metals, Proceeding of the Romanian Academy, Series A, 10, 3, (2009)

11. V. V. Hašek, Berichte aus dem Institut für Umformtechnik, Universität Stuttgart (On the stain and stress states in drawing of large un-regular sheet metal components), Essen: Giradet, (1973)

12. C. Garjob, S. G. Racz and O. Bologa, The Determination of the Forming Limit Curve 
Using a Modular Device, Ac. Jou. Manuf. Eng.., 8, 2, 39-44, (2010)

13. GOM GmbH, Gom Optical Measuring Techniques - ARAMIS FLC Computation, Braunschweig, (2007) 